\title{
TRABALHO ESCRAVO E TRABALHO LIVRE NO BRASIL - ALGUNS PARADOXOS HISTÓRICOS DO DIREITO DO TRABALHO
}

Sidnei Machado

Mestre em Direito das Relações Sociais e Doutorando pela UFPR, Advogado.

SUMÁRIO: 1 O Silêncio do Direito do Trabalho; 2 Emergência e Esgotamento da Exploração do Trabalho Escravo; 3 A Transição para o Trabalho Livre; 4 A Regulamentação do Trabalho Livre na Lei de Locação de Serviços; 5 O Contratualismo Requentado; Referências Bibliográficas.

\section{O SILÊNCIO DO DIREITO DO TRABALHO}

Este texto não tem a pretensão de recontar a história do trabalho livre no Brasil. Nosso propósito é reler um importante período de nossa história não com os olhos de hoje, mas numa perspectiva de um olhar refletido para o presente. Fazemos, assim, um recorte histórico para fixar dois destacados momentos da exploração e da regulamentação jurídica da venda da força de trabalho: a) o período de formação e exploração da mãode-obra escrava; b) o período de transição da escravidão para o trabalho livre.

A regulação do trabalho livre no Brasil no final do último quartel do século XIX evidencia de início um paradoxo: o advento da propalada libertação do trabalho escravo se dava via uma regulamentação rígida na contratação e na disciplina imposta aos trabalhadores. Mas a história "oficial" é de que, enfim, estávamos libertando nossos escravos, rumo a uma forma racionalizada e humana de trabalho: o trabalho livre.

A história do direito do trabalho no Brasil, salvo poucas exceções, aparece descrita como um processo linear, cronológico, dando conta da saga da formação de um direito a partir do rompimento com a exploração desumana do trabalho escravo, como se após a obscura escravidão negra do passado nascesse, enfim, o direito do trabalho. O direito do trabalho dos manuais é apresentado como fruto da intervenção estatal a partir das primeiras leis no começo do século XX, com destaque para a década de 30, no ambiente de um direito social em emergência, preocupado com a condição humana do operariado. As histórias do direito do trabalho e da justiça do trabalho aparecem, dessa forma, como fatos simultâneos e convergentes do mesmo processo histórico. Essa na verdade é mais uma história do emprego no Brasil e não do trabalho, este compreendido como modo de produção e reprodução da vida. ${ }^{1}$

1 SEGADAS VIANNA em seu Instituições de Direito do Trabalho, ao discorrer sobre os Antecedentes Históricos do Direito do Trabalho, em mais de 1.300 páginas, dedica menos de duas páginas ao trabalho 
Assim, a história do trabalho anterior ao trabalho livre tem poucas referências na historiografia do direito do trabalho, merecendo uma referência, na maioria das vezes, meramente ilustrativa do curso de direito do trabalho. Ignora-se, por completo, a vasta historiografia nas ciências sociais com pesquisas importantes sobre o modo de produção baseado no trabalho escravo e sua conturbada transição para o trabalho livre. Esse silêncio do direito do trabalho é, na verdade, eloqüente. Primeiro, é ocultado (as vezes negado) todo processo socioeconômico que deu caldo à formação do trabalho livre no Brasil, cujo contexto, lido da perspectiva das vítimas de história, revela que não tivemos grandes rupturas na regulamentação do trabalho, senão renovados processos de recomposição no modo de produção. Por fim, esse resgate pode permitir ler e compreender as recentes mutações no emprego, no mercado de trabalho e na contratação do trabalho no Brasil, na era da nova hegemonia neoliberal.

\section{EMERGÊNCIA E ESGOTAMENTO DA EXPLORAÇÃO DO TRABALHO ESCRAVO}

A utilização do trabalho escravo no Brasil colonial se deu dentro do projeto de expansão comercial e agrícola dos países colonizadores, especialmente Portugal. CELSO FURTADO, no seu clássico "Formação Econômica do Brasil", esclarece que "a ocupação econômica das terras americanas constitui um episódio da expansão comercial da Europa". ${ }^{2}$

O primeiro interesse dos espanhóis e portugueses pela América foi o ouro acumulado. A mera exploração do ouro, no entanto, não assegurou a Portugal a manutenção da colônia, ameaçada de ocupação. Nesse período, somente a ocupação representava verdadeiro domínio. Por outro lado, os gastos de defesa eram bastante elevados.

Como os portugueses já possuíam experiência no cultivo do açúcar em grande escala nas ilhas do Atlântico, a junção desse conhecimento técnico dos portugueses com a capacidade de transporte dos holandeses na Europa permitiriam a produção do açúcar em larga escala no Brasil. O principal problema para essa expansão seria a mãode-obra, pois não havia na colônia e o transporte de Portugal era economicamente inviável.

Na expansão da plantação do açúcar no Brasil, Portugal utilizou-se, inicialmente, do trabalho de índios escravizados. Mas o sistema de monopólio da produção do açúcar

escravo, com um parágrafo apenas onde se menciona a escravidão negra no Brasil. AMAURI MASCARO DO NASCIMENTO, em seu Curso de Direito do Trabalho, no capítulo introdutório que trata da História do Direito do Trabalho, não faz qualquer referência à relação de trabalho no Brasil anterior às primeiras leis do século XX. Esses dois exemplos são caricatos para demonstrar como os autores nacionais pouco se dedicaram ao trabalho escravo e livre. Além disso, as pequenas referências ao uso da mão-de-obra escrava são do modo de produção na Europa antes da revolução industrial, o que revela também uma visão eurocêntrica da história do direito do trabalho, já que desprezam o modo peculiar com que o Brasil se insere tardiamente na modernização capitalista.

2 FURTADO, Celso. Formação econômica do Brasil, p. 3. 
entrou em decadência com o início da produção nas ilhas das Antilhas, fazendo com que o preço do produto caísse. A necessidade política de colonização das terras e verificada a ausência de uma mão-de-obra excedente na península ibérica na época, levou Portugal a optar pela introdução da mão-de-obra escrava africana (negra).

Portanto, a primeira etapa da formação econômica do Brasil se dá pela utilização de mão-de-obra preexistente na exploração de minérios e pela produção de artigos agrícolas tropicais com uso de mão-de-obra escrava. No século XVIII, a exploração do ouro permitiu ao país grande expansão. Até a metade do século XIX, pelo menos, a estrutura econômica do país estava ainda centrada no uso da mão-de-obra escrava.

Com todas as dificuldades de cooptação do silvícola - custo de transporte e o meio físico - a indústria açucareira teve grande expansão. Inviável a utilização do indígena, a escassez de mão-de-obra era então o maior desafio. Por isso, a escravidão tornou-se a única alternativa para a sobrevivência do colono europeu na América. Os escravos montaram as indústrias açucareiras, tornando-se a base de um sistema de produção. Porém havia o uso de trabalhadores assalariados, estes na proporção de um a cada dez escravos.

Assim, o processo de formação da renda e de acumulação de capital se deu com gastos em compra de equipamentos para a indústria, com a aquisição de materiais de construção e de mão-de-obra escrava. O proprietário de engenho, além da compra do escravo, tinha que manter a sua subsistência, o que gerava um elevado custo fixo.

Paralelamente à indústria açucareira, começou-se a introduzir a produção da pecuária extensiva. Essa atividade utilizava mão-de-obra local, formada majoritariamente pelos índios. A atividade de criação (principalmente a pecuária extensiva) criou novas formas de divisão do trabalho e especialização, desenvolvendo uma economia puramente de subsistência.

No século XVII, as invasões holandesas interromperam a expansão da indústria açucareira. Aliada ao baixo preço e a perda do monopólio, acarretaram uma crise política na colônia. A crise fez com que a caça aos índios se tornasse condição de sobrevivência dos povoados. Os jesuítas chegaram a desenvolver técnicas racionais de caça do indígena. Essa cooperação da mão-de-obra indígena foi o que permitiu a grande expansão territorial no século XVII.

\section{A TRANSIÇÃO PARA O TRABALHO LIVRE}

O século XVII é uma nova etapa de crise econômica. Cai a renda per capita para cinqüenta dólares, para uma população livre de dois milhões. A economia estava ainda centrada no ouro, na indústria açucareira e, em pequena escala, na criação de gado. Os acontecimentos políticos de 1808 a 1810 provocaram grande repercussão no Brasil. A concorrência inglesa provocou uma forte pressão pelo fim do tráfico e uso da mão-de-obra escrava no Brasil. É nesse contexto que o café começa a surgir como nova fonte de riqueza. 
Os acordos firmados por Portugal com a Inglaterra (1810-1827), obrigando a colônia a pagar tarifas protecionistas à Inglaterra, retardou o processo de desenvolvimento. A expansão cafeeira, por outro lado, encontra dificuldades pelo estancamento da importação de mão-de-obra escrava. A princípio, não havia uma solução alternativa.

Na plantação de café, ao contrário da indústria açucareira, não era necessário a utilização de equipamentos, apenas o uso da terra e de escravos. Sendo o café a alternativa, bastava ainda resolver a questão da mão-de-obra, os chamados "braços para a lavoura", questão de grande inquietação nacional, então em debate no país: como fazer a transição da economia brasileira para produção de café se não havia no país mão-de-obra disponível?

Em 1850, o Brasil tinha dois milhões de escravos. Na Europa, a revolução industrial passou a exigir cada vez mais mão-de-obra, o que a tornou escassa. Por outro lado, a mão-de-obra livre do país não servia aos propósitos da plantação cafeeira (tradição). A solução preconizada então foi a imigração européia. Começam a criar na época imperial colônias de imigrantes, trazidos com a convicção de uma natural superioridade da raça com uma ética própria para o trabalho.

Em 1824, foi criada a primeira colônia alemã em São Leopoldo, no Rio Grande do Sul. Em 1852, Vergueiro, começa a contratar diretamente imigrantes na Europa, financiado pelo governo ( 80 famílias alemãs). Através de contratos de parceria, os imigrantes vendiam seu trabalho para o futuro. Ficavam devendo as passagens, transporte, comissões de contrato, além de outras despesas com o transporte.

Nesse contexto, os escravos libertos passaram a não ter trabalho, ficando sem condições de inserção social e de sobrevivência. $\mathrm{O}$ trabalho foi fornecido ao trabalhador europeu, pois era mais vantajoso ao proprietário, dadas as condições contratuais onerosas impostas aos imigrantes.

O escravo negro não tinha cultura e estímulo para participar de um modelo de parceria, por exemplo, pois "quase não possuindo hábitos de vida familiar, a idéia de acumulação de riqueza é praticamente estranha. Demais, seu rudimentar desenvolvimento mental limita extremamente suas 'necessidades'. Sendo o trabalho para o escravo uma maldição e o ócio o bem inalcançável, a elevação de seu salário acima de suas necessidades - que estão definidas pelo nível de subsistência de um escravo - determina de imediato uma forte preferência pelo ócio". ${ }^{3}$ Por isso, o exescravo passa a viver para suprir apenas as suas necessidades, renunciando ao modelo de parceria.

Com isso, o trabalho assalariado foi no fim do século XIX o fator econômico de maior importância. Os assalariados geravam gastos em consumo e o proprietário em consumo e acumulação. 


\section{A REGULAMENTAÇÃO DO TRABALHO LIVRE NA LEI DE LOCAÇÃO DE SERVIÇOS}

A extinção do uso da mão-de-obra escrava no Brasil se deu por um processo lento e gradual, com vistas à transição para a formação de um mercado de trabalho livre. Por isso, a segunda metade do século XIX é um período marcado pela preocupação de constituição e regulamentação legal do uso do trabalho livre no Brasil. A regulação dessas novas modalidades de uso da mão-de-obra contou com a mediação do Estado (Império) disciplinando os contornos do trabalho livre. Conquanto haja uma inexplicável lacuna na bibliografia do direito do trabalho, as leis de locação e serviços de 1830 , 1837 e 1879, representam o principal marco na experiência de intervenção estatal na contratação do trabalho livre no Brasil.

O período de transição da escravidão para o trabalho livre é longo. A importação de mão-de-obra Européia tem início nos anos de 1850, sendo talvez a primeira experiência na importação de colonos pela firma Vergueiro \& Cia. Os colonos eram cativados para o paraíso de terras férteis e abundantes, oferecendo trabalho livre, passando a conviver com a mão-de-obra escrava nas fazendas.

Os primeiros imigrantes trazidos por empresas importadoras em geral eram obrigados a assinar contratos de parceria com o importador para trabalhar nas lavouras do café do Estado de São Paulo. O contratante adiantava as despesas de transporte da Europa às colônias e o necessário à subsistência inicial. Nas colônias, o imigrante recebia determinado número de pés de café para cultivar. Tinha direito a meação no resultado da venda. As dívidas contraídas na imigração eram pagas com juros de $6 \%$ ao ano, não podendo o colono deixar de cumprir o contrato antes de saldá-las integralmente, além de comunicar o contratante com seis meses de antecedência. O não-cumprimento do contrato gerava multa ao colono. Outras cláusulas apareciam nos regulamentos das colônias, tais como as que impunham um controle disciplinar rigoroso, com aplicação de penas severas aos infratores.

As experiências iniciais do trabalho livre do colono foram marcadas por inúmeros conflitos, desentendimentos, greves, denúncias de cobranças de taxas abusivas pelo importador, rebeldia contra controle moral e disciplinar severo imposto nas colônias, fatos que inclusive redundaram na acusação de Portugal ao Brasil da prática de uma escravidão disfarçada. O descumprimento do contrato pelo colono, por exemplo, poderia representar-lhe, além da rescisão, multa e a pena de prisão de oito dias a três meses. Contudo, para os fazendeiros o clima era de insegurança generalizada no cumprimento dos contratos, o que reclamaria uma regulamentação jurídica mais eficiente do que a então vigente.

Até então, o espaço jurídico do trabalho livre era representado somente pela Lei de 1830 e a de 1837 . A primeira regulamentava apenas os contratos entre nacionais e estrangeiros, e a segunda dispunha apenas sobre trabalho de estrangeiros. A Lei de 13 de setembro de 1830 possuía apenas oito artigos, sem grande disciplina dos contratos, já que sequer especificava seus prazos. No entanto, a Lei de 1837, possuía 17 artigos 
sobre contratos de locação de serviços. Porém, essas leis não tiveram grande repercussão, dado que tinham um conteúdo bastante vago.

A relação conflituosa entre fazendeiros e colonos, aliada à crescente dificuldade de importação de escravos negros da África a partir da década de 60, exige que se use da mão-de-obra nativa, forçando-os ao trabalho na lavoura, eliminando assim a vadiagem, considerada um mal. ${ }^{4}$ Os fazendeiros também reclamavam uma legislação que permitisse garantias dos investimentos feitos na mão-de-obra, no cumprimento dos contratos, na repressão às greves e, ainda, que lhes propiciassem uma adequada produtividade. A promulgação da lei do vente livre, em 1871, sinalizando a abolição da escravidão, criou as condições para uma legislação que, ao mesmo tempo em que fazia a regulação minuciosamente da contratação do trabalho livre, previa a obrigação do homem livre de contratar, como mecanismo de combate à vadiagem. ${ }^{5}$

Após quase dez anos de discussão, em 1879, foi enfim editado o Decreto $\mathrm{n}^{\circ}$ 2.820 , de 22.03.1879, com oitenta e seis artigos, regulamentando os contratos na agricultura, de trabalhadores libertos nacionais e estrangeiros, disciplinando a locação de serviços e as modalidades de parcerias agrícolas e pecuárias. Conhecida como a Lei Sinimbu, a lei contemplava além das obrigações contratuais entre trabalhadores e fazendeiros, disposições antigreves e contra quaisquer resistências coletivas ao trabalho. Continha, ainda, um capítulo dedicado à matéria penal e outro a competências e procedimentos processuais.

Os contratos de locação de serviços e de parceria poderiam ser feitos por nacionais e estrangeiros, sempre por escritura pública, registrado na Câmara Municipal. Os contratos poderiam ter duração de seis anos para brasileiros, cinco para estrangeiros e sete para os libertos. Eram consideradas como justas causas do locador, justificando a rescisão contratual pelo locatário, a doença prolongada, a embriaguez, a imperícia e a insubordinação. A pena de prisão era aplicável caso o locador se ausentasse sem justo motivo ou se, permanecendo na propriedade, se recusasse ao trabalho, dentre outras faltas consideradas graves. Previa a lei a obrigação de contratar, somente deixando de ser aplicada caso o trabalhador livre estivesse servindo o exército. Os libertos continuavam com sua situação regulada pela Lei do Ventre Livre, ficando sob inspeção por cinco anos, com a obrigação de firmar novo contrato.

É visível o grande esforço revelado pela lei para garantir aos fazendeiros a manutenção do controle da mão-de-obra dos trabalhadores livres e libertos, agora

4 É exemplar o discurso à época na Câmara dos Deputados: “... esta multidão que vide no ócio, na moleza e na miséria que tem por constante residência a taverna, e por única distração ou trabalho ou jogo, é nessa multidão que devemos procurar os colonos, confeccionando-se leis repressivas da vadiagem ..." Anais da Câmara dos Deputados, sessão de 19 de agosto de 1861, p. 221.

5 "A legislação actual é completamente inefficaz contra a vadiação. O vadio só pode ser preso por alguns dias se o quebrar (...) Se o vadio assinasse termo de procurar trabalho dentro de certo prazo, e se, findo esse prazo, não provasse ser constrangido em presença da autoridade a assinar um contrato de locação de serviços com o pretendente que, na ocasião, maiores vantagens offerecesse, colher-se-ia resultados seguros”. Relatório da Repartição da Polícia da Província de S. Paulo, de 2 de fevereiro de 1872, p. 24, apud. LAMOUNIER, Maria Lúcia. Da escravidão ao trabalho livre, p. 74. 
mediante rígidas obrigações contratuais. Após, libertos passam a ser obrigados a trabalhar, de forma disciplinada e produtiva. Algumas disposições funcionaram como garantia do fazendeiro ou importador do pagamento de despesas de viagens do estrangeiro imigrante, assegurando a prestação de serviço. Tudo ditado pelos imperativos das exigências de "liberdade de trabalho". Nesse contexto, a legislação sobre relações de trabalho tratada na lei de locação de serviços, redefine relações de poder e introduz uma nova organização e um novo controle sobre o trabalho. Sem dúvida, trata-se de um momento histórico relevante na história do direito do trabalho, este entendido como a relação de compra e venda da mão-de-obra.

A Lei de 1879 certamente permitiu a transição do trabalho escravo ao trabalho livre, numa política que constrangia os nacionais ao trabalho e, por outro lado, incentivava os imigrantes europeus ao trabalho na colônia. O longo período de transição possibilitou também uma adaptação dos fazendeiros à nova relação de trabalho. No entanto, nos anos que se seguiram, a lei passou a receber críticas dos fazendeiros pelo nível de intervenção do Império. Houve também um refluxo na imigração. A lei, então, perde vigor, sendo finalmente revogada em 1890. A grande imigração italiana do final do século já se dá por modalidade de contratos de parceria entre colono e fazendeiro.

\section{O CONTRATUALISMO REQUENTADO}

Não se pode celebrar acriticamente a liberdade de trabalho como um valor em si mesmo, sem perder de vista o papel desempenhado pelo contratualismo na formação e justificação política e teórica da venda da força de trabalho (livre) através do instrumento do contrato de trabalho. Os dados historiográficos nos forçam a reconhecer que a formação da contratação (ou relação) individual do trabalho no Brasil não é fruto de "evolução histórica" que se confundiria com a conquista da liberdade humana ou a liberdade de trabalho.

Mais do que curiosidades históricas, temos uma história particular, dissociada dos processos de desenvolvimento que se deram nos países então em processo de industrialização. Enquanto nesses países o trabalho livre assalariado é introduzido como uma necessidade de desenvolvimento e expansão do capitalismo ainda incipiente, nestes trópicos predominaram os interesses de ocupação da terra e sua exploração. ${ }^{6}$

A legislação do trabalho livre no Brasil aparece mediando o paradoxo da liberação do trabalho com imperativo de liberdade e, por outro lado, se dá por um processo que teve como preocupação a garantia de mão-de-obra, impondo a disciplina e a obrigação de trabalho, tudo com garantias contratuais.

Em verdade pode se reconhecer que a história do direito do trabalho representa, em essência, um processo de adaptação de uma sociedade rural aos imperativos do capitalismo da sociedade industrial.

6 Max Weber bem demonstrou como na era moderna o capitalismo é identificado como "uma organização capitalista racional assentada no trabalho livre (formalmente pelo menos)". Ver WEBER, Max, A ética protestante e o espírito do capitalismo, p. 17. 
As demandas atuais por maior flexibilidade na contratação do trabalho, curiosamente aparecem sobre o paradoxo de uma exigência por novas regulamentações. Não se ignora, obviamente, a efetiva mutação no mercado de trabalho a partir do fim do século XX, com os impactos profundos no conteúdo do trabalho, no tempo de trabalho e na organização produtiva (organização do trabalho e novas tecnologias). Porém, a nova regulamentação em curso é mediada pelo Estado, vale dizer, pelo direito do trabalho. Novamente o direito aparece com o papel de fazer a transição paradigmática.

\section{REFERÊNCIAS BIBLIOGRÁFICAS}

ARENDT, Hannah. A condição humana. Rio de Janeiro: Forense, 1981.

CARVALHO FRANCO, Maria Sylvia de. Homens livres na ordem escravocrata. 4. ed. São Paulo: Unesp, 1997.

FURTADO, Celso. Formação econômica do Brasil. Rio de Janeiro: Nova Fronteira, 2000.

LAMOUNIER, Maria Lúcia. Da escravidão ao trabalho livre: a lei de locação de serviços de 1879. Campinas: Papirus, 1988.

MÜLLER, Friedrich. Quem é o povo? a questão fundamental da democracia. Rio de Janeiro: Max Limonad, 1998.

NABUCO, Joaquim. O abolicionismo. Rio de Janeiro: Nova Fronteira, 2000.

QUEIROZ, Suely Robles Reis de. Escravidão negra no Brasil. São Paulo: Ática, 1987.

TOCQUEVILLE, Alexis de. A emancipação dos escravos. Campinas: Papirus, 1994.

WEBER, Max. A ética protestante e o espírito do capitalismo. 12. ed. São Paulo: Biblioteca pioneira de ciências sociais, 1996.

. Sociologia do trabalho industrial. Madrid: Trotta, 1988. 